\title{
The effect of curved tips on the dynamics of composite rotor blades
}

\author{
M.R. Amoozgar ${ }^{\mathrm{a}}$, A. Shaw ${ }^{\mathrm{b}}$, M.I. Friswell ${ }^{\mathrm{b}}$ \\ ${ }^{\text {a }}$ School of Computing and Engineering, University of Huddersfield, Huddersfield HD1 3DH, UK \\ ${ }^{\mathrm{b}}$ College of Engineering, Swansea University, Swansea SA1 8EN, UK
}

\begin{abstract}
In this paper, the dynamics of a tailored composite rotating blade with curved tips are investigated, with a view to improving the dynamic behaviour of the blade in flight. The blade tip is curved either in the out-of-plane or in the in-plane directions. The composite blade is modelled by using the exact beam fomulation, and the cross-sectional properties of the blade are obtained using the variational asymptotic method. The resulting nonlinear partial differential equations are discretised using a time-space scheme, and the stationary and rotating frequencies of the blade are obtained from the eigenvalues of the linearised system. Three case studies are considered here each of them representing one of the main elastic couplings that might happen in a composite blade. These three elastic couplings are the flap-twist, lag-twist, and extension-twist couplings. All these couplings are very important in the blade design as they can affect the twist and hence the dynamics of the blade. The blade tip length and curvature value are two main parameters that this paper is focused on. It is shown that the curved tip of the blade affects the blade frequencies by adding extra couplings, and therefore could be used as a potential morphing concept for tuning the frequencies, enhacing the aeroelastic stability or performance of the blade in flight.
\end{abstract}

Keywords: Rotating frequencies, veering, fully intrinsic equations, composite blade, elastic couplings.

\section{Introduction}

From the earliest developments in the rotorcraft industry, one of the main issues that designers face has been the reduction of noise and vibration [1-5]. This noise and vibration problem might limit the usage of rotorcraft despite the other advantages that these vehicles have compared to fixed-wing vehicles. One of the solutions for this issue is to use advanced blade tips which can influence the performance and noise level of rotorcraft. Adding a sweep angle to the tip of the blade can delay the compressibility effects and also to reduce the Mach tuck ( a severe nose down moment due to shock formation ), and hence affect the aerodynamic performance of the rotor [6]. Furthermore, a blade tip with anhedral limits the tip vortex blade interaction, and hence influences the 
aerodynamics of the rotor [6]. From the structural point of view, a blade tip with sweep or anhedral affects the mass and inertial distributions of the blade and also adds additional elastic couplings in the structure that can affect the dynamics of the blade [7]. Tarzanin and Vlamick [8] showed how the tip sweep of the blade influences the hub loads of an articulated rotor system. Although the method that they adapted to consider the effect of tip sweep was simple, they showed that the blade tip sweep affects both the vibrations and stability of the blade. A consistent model which was able to account for the effect of tip sweep for hingeless rotor blades was developed by Celi and Friedman [9]. This work was one of the first studies that used a systematic approach to represent the tip sweep. However some simplifications were considered in this formulation that were later [10] shown to be insufficiently accurate for large sweep angles. The aeroelastic analysis of hingeless rotor blades equipped with both tip sweep and anhedral was performed by Benquet and Chopra [11]. They used a linear transformation to combine the effect of tip sweep with the blade. This work was refined by adding the nonlinear transformation instead of the linear transformation by Kim and Chopra [12]. The effect of tip geometries on the vibration and aeroelasticity of composite blades was investigated by Yuan et al. [13]. They showed that the composite ply angle combined with the effect of tip devices can result in different aeroelastic results. Friedman et al. [14] studied the effect of swept blade tips on the aeroelastic stability by combining the nonlinear moderate deflection beam theory with the free wake inflow model to improve the aeroelastic model. It was shown that due to the frequency coalescence, the blade might enter into an aeroelastic instability region when the blade is equipped with swept tips. Shang et al. [7] investigated the effects of tip sweep and dihedral angles on the dynamics and aeroelastic stability of hingeless rotor blades. They developed a model based on large deformation beam theory combined with an unsteady finitestate dynamic wake model. Kumar and Venkatesan [6] studied the trim and control of a helicopter blade when the blades are equipped with tip devices. They showed that the tip dihedral/anhedral combined with the tip sweep may influence both the hub loads and the flight dynamics of the helicopter. Brocklehurst and Barakos [15] reviewed different tip shapes that can be designed for a helicopter blade depending on the requirements. The effect of the shape of the helicopter blade tip planform on the noise in forward flight has been studied by Zhu and Zhao [16]. They showed that the optimised shape of double-swept and tapered tips can result in a reduction of sound pressure. More recently, Filippi et al. [17] developed multidimensional finite element models to analyse the helicopter blades equipped with double-swept tips. They showed numerically and experimentally that their developed tool works fine for modern helicopter blades.

Apart from designing a blade with fixed geometry, it is possible to change the shape of the blade in flight to reduce the noise and vibration level, or to enhance the performance. By modifying the blade shape in flight, both the aerodynamics and the dynamics of the blade can be affected which in turn might improve the helicopter 
characteristics. There are several blade morphing concepts proposed in the literature. Chen and Chopra [18, 19] proposed using piezoelectric actuators to twist the blade and showed that some tangible twist change can be obtained. Using shape memory alloys to change the shape of the blade was proposed by Prahlad and Chopra [20]. They showed that the process of heating and cooling the torque tube results in different twist values. Mistry et al. [21] developed a twist morphing concept based on the warping of the blade skin by using a threaded rod-spar. Using a variable chord blade might have the advantage of alleviating the stall characteristics of the blade. To meet this objective, Barbarino et al. [22] proposed a concept to extend the chord of the blade using a cellular structure. Using a Von Mises truss connected to a deployable plate is another concept to change the chord of the blade in flight which was proposed by Moser et al. [23]. In this mechanism, when the rotating speed of the rotor reaches a predefined value, the plate is deployed through a slit located in the trailing edge of the section. Rivero et al. [24] considered the structural modelling of a camber morphing concept which was previously developed by Woods et al. [25]. This concept affects the aerodynamic efficiency of the blade in flight. More recently, Amoozgar et al. $[26,27]$ developed a twist morphing concept that works for composite helicopter blades. In this study, a mass is added to the blade, so that by moving the mass in the chordwise direction, the twist of the blade can change. In contrast to the previous concepts that have been proposed to morph helicopter blades, it is possible to change the shape of the blade tip to reduce both the noise and vibration levels of the blade, and also to enhance the performance and the aeroelastic stability of the blade. It has been shown previously that the blade tip can influence the aeroelastic stability [7] and vibration [14] of the rotor.

This paper shows how a combination of a raked blade tip and tailored composite layup can be exploited to control vibration modes. To show that this shape changing of the blade tip can be effective on the dynamics properties of the blade, a systematic approach is followed to examine the effect of curved tips on the rotating frequencies (frequencies of the rotating blade) of composite blades. The tip curvature adds new couplings which cause change in the rotating frequencies of the blade. Furthermore, the blade composite layup may also introduce some other elastic couplings into the system. Therefore, in this study, the combination of these two different types of couplings on the rotating frequencies of composite blades are investigated.

\section{Problem Statement}

A hingeless rotor blade modelled as a cantilevered beam, as shown in Figure 1, is considered. The blade chord is denoted by $c$, and the blade length by $L$. It is noted that in this study, the effect of aerodynamic loads on the blade is neglected. The blade rotates at a constant angular velocity, $\Omega_{\text {ref, }}$ and the origin of the coordinate system is located at the root of the blade. The $x$ axis of the coordinate system is towards the tip of the blade, and the $y$ axis 
lies in the chordwise direction and is positive towards the leading edge. The blade is equipped with tip devices that are curved in the out-of-plane or in-plane directions. The blade internal structure is composed of a composite box-beam. The length of the curved segment of the blade is denoted by $d l$, while the curvatures in the out-of-plane and in-plane directions are defined by $k_{2}$ and $k_{3}$, respectively. The tip segment length is defined from the tip of the blade and is nondimensionalized with respect to the blade length. In this study, it is assumed that the tip segment of the blade has a constant initial curvature. Figure 1(a) shows the schematic of the blade when the tip is swept linearly or curved. While Figure 1(b) shows the blade equipped with a curved out-of-plane tip and its corresponding anhedral shape. It is noted that, in this study, the swept and anhedral tips denote a tip with a constant curvature with respect to the blade.

a)

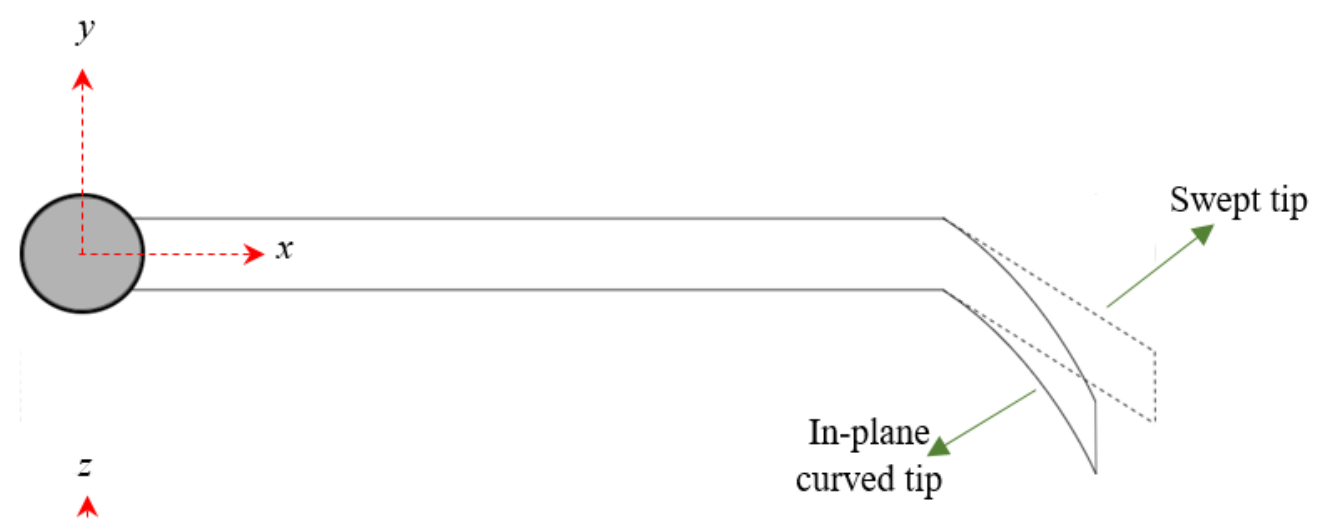

b)

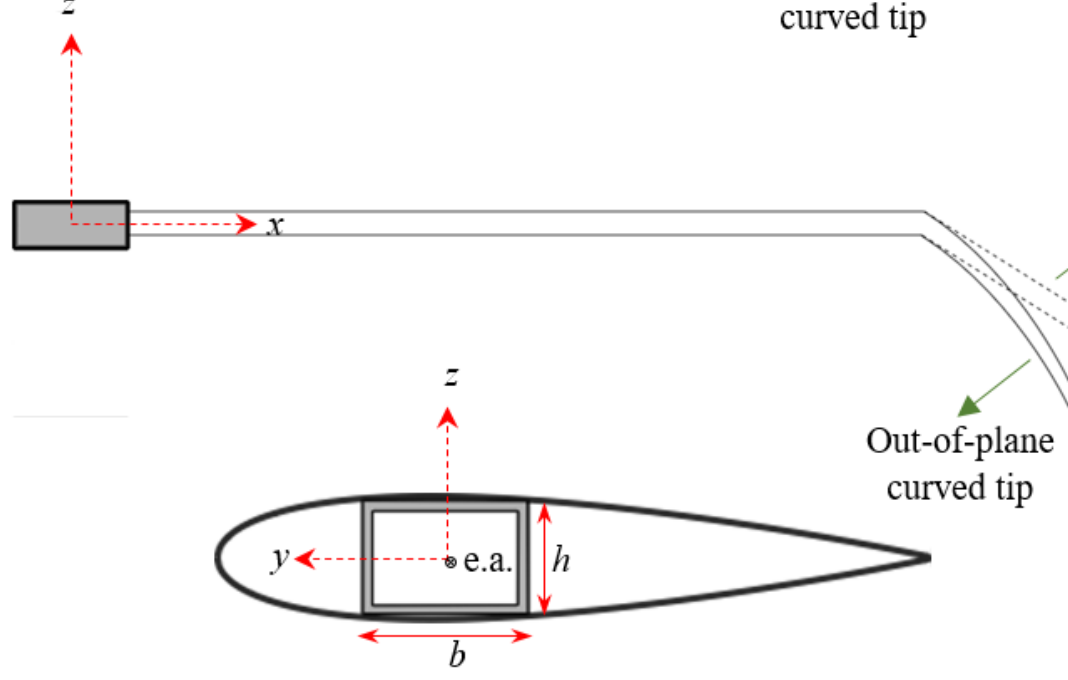

Figure 1: Schematic of the composite blade with tip devices a) swept and in-plane curved tip b) with anhedral and out-ofplane curved tip c) cross-section of the blade

\section{Mathematical Modelling}

The structural dynamics of the composite blade is modelled using a cantilevered beam simulated through the geometrically exact fully intrinsic beam equations [28]. This beam formulation has been considered for many 
aerospace applications [26, 29-32]. With this formulation it is easy to consider the effect of initial twist and curvature of the beam. The nonlinear differential equations of the composite blade can be expressed as

$$
\begin{aligned}
& \partial F_{1} / \partial x_{1}+K_{2} F_{3}-K_{3} F_{2}=\partial P_{1} / \partial t+\Omega_{2} P_{3}-\Omega_{3} P_{2} \\
& \partial F_{2} / \partial x_{1}+K_{3} F_{1}-K_{1} F_{3}=\partial P_{2} / \partial t+\Omega_{3} P_{1}-\Omega_{1} P_{3} \\
& \partial F_{3} / \partial x_{1}+K_{1} F_{2}-K_{2} F_{1}=\partial P_{3} / \partial t+\Omega_{1} P_{2}-\Omega_{2} P_{1} \\
& \partial M_{1} / \partial x_{1}+K_{2} M_{3}-K_{3} M_{2}+2 \gamma_{12} F_{3}-2 \gamma_{13} F_{2}=\partial H_{1} / \partial t+\Omega_{2} H_{3}-\Omega_{3} H_{2}+V_{2} P_{3}-V_{3} P_{2} \\
& \partial M_{2} / \partial x_{1}+K_{3} M_{1}-K_{1} M_{3}+2 \gamma_{13} F_{1}-\left(1+\gamma_{11}\right) F_{3}=\partial H_{2} / \partial t+\Omega_{3} H_{1}-\Omega_{1} H_{3}+V_{3} P_{1}-V_{1} P_{3} \\
& \partial M_{3} / \partial x_{1}+K_{1} M_{2}-K_{2} M_{1}+\left(1+\gamma_{11}\right) F_{2}-2 \gamma_{12} F_{1}=\partial H_{3} / \partial t+\Omega_{1} H_{2}-\Omega_{2} H_{1}+V_{1} P_{2}-V_{2} P_{1} \\
& \partial V_{1} / \partial x_{1}+K_{2} V_{3}-K_{3} V_{2}+2 \gamma_{12} \Omega_{3}-2 \gamma_{13} \Omega_{2}=\partial \gamma_{11} / \partial t \\
& \partial V_{2} / \partial x_{1}+K_{3} V_{1}-K_{1} V_{3}-\left(1+\gamma_{11}\right) \Omega_{3}+2 \gamma_{13} \Omega_{1}=2 \partial \gamma_{12} / \partial t \\
& \partial V_{3} / \partial x_{1}+K_{1} V_{2}-K_{2} V_{1}+\left(1+\gamma_{11}\right) \Omega_{2}-2 \gamma_{12} \Omega_{1}=2 \partial \gamma_{13} / \partial t \\
& \partial \Omega_{1} / \partial x_{1}+K_{2} \Omega_{3}-K_{3} \Omega_{2}=\partial \kappa_{1} / \partial t \\
& \partial \Omega_{2} / \partial x_{1}+K_{3} \Omega_{1}-K_{1} \Omega_{3}=\partial \kappa_{2} / \partial t \\
& \partial \Omega_{3} / \partial x_{1}+K_{1} \Omega_{2}-K_{2} \Omega_{1}=\partial \kappa_{3} / \partial t
\end{aligned}
$$

where, $x_{l}$ is the direction of the beam reference line along the span, $\mathbf{F}$ and $\mathbf{M}$ are vectors containing the internal forces and moments, $\mathbf{V}$ and $\mathbf{\Omega}$ are vectors of inertial velocity and angular velocity, and $\mathbf{P}$ and $\mathbf{H}$ are vectors representing the sectional linear and angular momenta, respectively. All of these vectors, together with the curvature vector $\mathbf{K}$ of the deformed beam, are written in uppercase and are expressed in the deformed beam reference system. On the other hand, the curvature vector $\mathbf{k}$ of the undeformed beam and the generalized strains of the beam $\boldsymbol{\gamma}$ and $\boldsymbol{\kappa}$ are written in lowercase and are expressed in the undeformed beam reference system. The twist and bending measures are defined in terms of $\mathbf{\kappa}$ through the curvature vectors as

$$
K_{i}=\kappa_{i}+k_{i} \quad i=1,2,3
$$

where $k_{i}$ for $i=1,2,3$ are the initial twist and curvatures of the undeformed beam, and $K_{i}$ for $i=1,2,3$ are the twist and curvatures of the deformed beam. It must be noted that the initial twist is taken to be zero here. However, in this study it is assumed that the blade is partly curved from the tip, and therefore the curvature vector for the undeformed blade is zero for all discretised elements except those elements corresponding to the tip segment. The 
cross-sectional properties of the blade composite spar is determined by VABS (version 3.7) [33], which are then introduced in the beam formulation through the stiffness matrix as

$$
\left[\begin{array}{l}
F_{1} \\
F_{2} \\
F_{3} \\
M_{1} \\
M_{2} \\
M_{3}
\end{array}\right]=\left[\begin{array}{llllll}
S_{11} & S_{12} & S_{13} & S_{14} & S_{15} & S_{16} \\
S_{12} & S_{22} & S_{23} & S_{24} & S_{25} & S_{26} \\
S_{13} & S_{23} & S_{33} & S_{34} & S_{35} & S_{36} \\
S_{14} & S_{24} & S_{34} & S_{44} & S_{45} & S_{46} \\
S_{15} & S_{25} & S_{35} & S_{45} & S_{55} & S_{56} \\
S_{16} & S_{26} & S_{36} & S_{46} & S_{56} & S_{66}
\end{array}\right]\left[\begin{array}{c}
\gamma_{11} \\
2 \gamma_{12} \\
2 \gamma_{13} \\
\kappa_{1} \\
\kappa_{2} \\
\kappa_{3}
\end{array}\right]
$$

where $\mathbf{S}$ contains the composite spar cross-section stiffness components. In this study, three cases for the composite blade are considered. In each of these cases, one of the main couplings of the box beam layup is dominant. In the first case, extension-twist coupling $\left(S_{14}\right)$ is present, in the second case flap-twist coupling is dominant $\left(S_{45}\right)$, while in the last case the lag-twist coupling $\left(S_{46}\right)$ is the main coupling in the stiffness matrix.

Furthermore, the linear and angular velocities of the beam are related to the linear and angular momenta within the mass matrix, which is written as

$$
\left[\begin{array}{l}
P_{1} \\
P_{2} \\
P_{3} \\
H_{1} \\
H_{2} \\
H_{3}
\end{array}\right]=\left[\begin{array}{cccccc}
\mu & 0 & 0 & 0 & \mu x_{3} & -\mu x_{2} \\
0 & \mu & 0 & -\mu x_{3} & 0 & 0 \\
0 & 0 & \mu & \mu x_{2} & 0 & 0 \\
0 & -\mu x_{3} & \mu x_{2} & i_{11} & 0 & 0 \\
\mu x_{3} & 0 & 0 & 0 & i_{2} & i_{23} \\
-\mu x_{2} & 0 & 0 & 0 & i_{23} & i_{3}
\end{array}\right]\left[\begin{array}{l}
V_{1} \\
V_{2} \\
V_{3} \\
\Omega_{1} \\
\Omega_{2} \\
\Omega_{3}
\end{array}\right]
$$

where $\mu$ and $\mathbf{i}$, are the mass per unit length, and the matrix of cross-sectional moment of inertia of the composite beam, respectively. $x_{i}$ for $i=1,2,3$ defines the offsets between the beam reference line and the mass centroid in each direction.

Finally, as the beam is clamped at the root to model the hingeless rotor blade, the fixed boundary conditions are applied to close the formulation. As the tip of the blade is free, the force (F) and moment (M) values are zero at the tip. Also, as the blade root is fixed and the helicopter is stationary, all the linear $(\mathbf{V})$ and angular $(\boldsymbol{\Omega})$ velocities are zero except $\Omega_{3}$ which is the rotating speed of the rotor. Therefore, the boundary conditions are as follows:

$$
\left[\begin{array}{l}
F_{1}(L, t) \\
F_{2}(L, t) \\
F_{3}(L, t)
\end{array}\right]=\left[\begin{array}{l}
0 \\
0 \\
0
\end{array}\right], \quad\left[\begin{array}{l}
M_{1}(L, t) \\
M_{2}(L, t) \\
M_{3}(L, t)
\end{array}\right]=\left[\begin{array}{l}
0 \\
0 \\
0
\end{array}\right], \quad\left[\begin{array}{l}
V_{1}(0, t) \\
V_{2}(0, t) \\
V_{3}(0, t)
\end{array}\right]=\left[\begin{array}{l}
0 \\
0 \\
0
\end{array}\right], \quad\left[\begin{array}{l}
\Omega_{1}(0, t) \\
\Omega_{2}(0, t) \\
\Omega_{3}(0, t)
\end{array}\right]=\left[\begin{array}{c}
0 \\
0 \\
\Omega_{r e f}
\end{array}\right]
$$

The nonlinear partial differential equations of the composite blade are solved using a $2^{\text {nd }}$ order space-time discretization scheme [28]. In this space-time scheme, any variable is defined at the left and right hand sides of each node. Then, the elemental value can be obtained by calculating the mean of nodal values connected to that specific element. This method is very useful especially when discontinuities are presented in the system. When 
all the equations are discretised using this method, first all time dependent variables are removed from the equations, and the steady-state condition of the system are obtained by solving the nonlinear algebraic equations using the Newton-Raphson method. Then, to calculate the stationary and rotating frequencies of the blade, the eigenvalues of the linearized system about the steady-state condition are determined.

\section{Validation}

In order to check the accuracy and validity of the developed code, two cases are considered here. In the first case, the rotating frequencies of a composite blade are determined, and compared with those reported by [34] and presented in Table 1. In this case, the composite box spar of the blade is composed of 6 layers and the thickness of each layer is $0.127 \mathrm{~mm}$. The outer width $(b)$ of the composite box section is $24.2 \mathrm{~mm}$ and the height $(h)$ is 13.5 $\mathrm{mm}$. The composite box has a layup that is symmetric about the cross-sectional mid planes and therefore the main coupling here is the flap-twist coupling. The length of the blade is $845 \mathrm{~mm}$, and it is rotating with a rotating speed of $\Omega_{r e f}=1002 \mathrm{rpm}$. The results are a good match with those obtained by a detailed finite element model [34]. It is noted that here, 14 elements have been used to simulate the dynamics of the blade.

Table 1: The rotating frequencies of the composite blade with symmetric layup of $[15]_{3},[15 /-15]_{3}$

\begin{tabular}{|c|r|c|}
\hline Mode & Present (Hz) & Detailed FEM (Hz) [34] \\
\hline Flap 1 & 35.407 & 36.0 \\
\hline Flap 2 & 195.518 & 197.3 \\
\hline Lag 1 & 56.722 & 57.1 \\
\hline Lag 2 & 351.099 & 349.3 \\
\hline Torsion 1 & 713.706 & 714.9 \\
\hline
\end{tabular}

In order to check the validity of the developed code for beams with initial curvature, the nondimensional natural frequencies $\left(\Phi=\sqrt{\frac{\mu \omega^{2} L^{4}}{E I}}\right)$ of a cantilevered beam are obtained and compared with [35] and shown in Table 2. In this case, the beam is isotropic and the curvature angle of the beam $\left(\eta=L . k_{2}\right)$ is $\eta=180^{\circ}$. In other words, the beam is formed to become a half circle. The comparison of the results shows a good agreement.

Table 2: The nondimensional natural frequencies of an isotropic cantilever beam with initial curvature

\begin{tabular}{|c|c|c|}
\hline Mode No. & Present & Rosa and Franciosi [35] \\
\hline $\mathbf{1}$ & 0.43541 & 0.435 \\
\hline
\end{tabular}




\begin{tabular}{|l|c|c|}
\hline $\mathbf{2}$ & 1.3781 & 1.375 \\
\hline $\mathbf{3}$ & 4.7311 & 4.71 \\
\hline $\mathbf{4}$ & 10.604 & 10.52 \\
\hline
\end{tabular}

\section{Numerical Results}

In what follows, the effect of the curved tip of the blade on the rotating frequencies of a composite blade is investigated. The spar-box of the blade, which is the main load carrying part of the structure, is made of AS4/35016 graphite/epoxy with material properties presented in Table 3. The outer width and height of the spar box are $b=12.804 \mathrm{~mm}$ and $h=8.944 \mathrm{~mm}$, respectively. Each wall consists of 6 layers with a thickness of $t=0.134 \mathrm{~mm}$ for each layer. The hingeless rotor blade characteristics are presented in Table 4.

Table 3: The material properties of AS4-3501-6

\begin{tabular}{|l|l|}
\hline Parameter & Value \\
\hline$E_{11}(\mathrm{GPa})$ & 142.0 \\
\hline$E_{22}=E_{33}(\mathrm{GPa})$ & 9.8 \\
\hline$G_{12}=G_{13}(\mathrm{GPa})$ & 6.0 \\
\hline$G_{23}(\mathrm{GPa})$ & 3.77 \\
\hline$v_{12}=v_{13}$ & 0.3 \\
\hline$v_{23}$ & 0.34 \\
\hline$\rho\left(\mathrm{kg} / \mathrm{m}^{3}\right)$ & 1445 \\
\hline
\end{tabular}

Table 4: The hingeless rotor blade characteristics

\begin{tabular}{|c|l|c|}
\hline Parameter & Description & Value \\
\hline$L(\mathrm{~m})$ & Blade length & 0.9615 \\
\hline$c(\mathrm{~m})$ & Blade chord & 0.0864 \\
\hline$\mu(\mathrm{kg} / \mathrm{m})$ & Blade mass unit per length & 0.343 \\
\hline$i_{11}(\mathrm{~kg} \mathrm{~m})$ & Blade polar mass moment of inertia per unit length & $2.062 \times 10^{-4}$ \\
\hline$\Omega_{\text {ref }}(\mathrm{rpm})$ & Rotor angular velocity & 1000 \\
\hline
\end{tabular}

To consider a systematic approach for this problem, as mentioned earlier, three cases are considered, where each represents one of the desired elastic couplings that might happen in a composite structure. In the first case, as shown in Table 5, the layup is selected so that the dominant coupling is flap-twist coupling. The lag-twist coupling is the dominant elastic coupling in the second case, while in the third case, extension-twist coupling is dominant. 
It is noted that in all these cases, the stacking sequences starts from the inside layer to the outside layer. The sign convention used to define the composite box layups is shown in Figure 2.

Table 5: Composite blade lamination and ply angles for the three different cases

\begin{tabular}{|l|l|l|l|l|}
\hline Configuration & Top & Bottom & Left & Right \\
\hline Case $1(\mathrm{~F}-\mathrm{T})$ & {$[\zeta]_{6}$} & {$[\zeta]_{6}$} & {$[\zeta /-\zeta]_{3}$} & {$[\zeta /-\zeta]_{3}$} \\
\hline Case 2 (L-T) & {$[\zeta /-\zeta]_{3}$} & {$[\zeta /-\zeta]_{3}$} & {$[\zeta]_{6}$} & {$[\zeta]_{6}$} \\
\hline Case 3 (E-T) & {$[\zeta]_{6}$} & {$[-\zeta]_{6}$} & {$[\zeta]_{6}$} & {$[-\zeta]_{6}$} \\
\hline
\end{tabular}

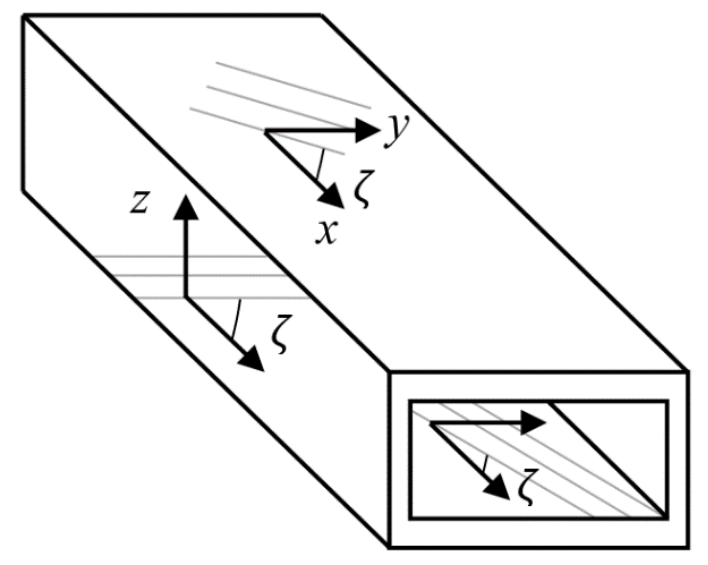

Figure 2: Sign convention used for the composite box

The corresponding stiffness matrices of the cases considered in Table 5 and for $\zeta=20^{\circ}$ are presented as follows

$$
\begin{aligned}
& {[S]_{\text {case } 1}=\left[\begin{array}{cccccc}
2.94 \times 10^{6} & 4.81 \times 10^{5} & 6.41 \times 10^{2} & 0 & 0 & 0 \\
4.81 \times 10^{5} & 2.66 \times 10^{5} & 6.07 \times 10^{2} & 0 & 0 & 0 \\
6.41 \times 10^{2} & 6.07 \times 10^{2} & 1.71 \times 10^{5} & 0 & 0 & 0 \\
0 & 0 & 0 & 1.31 \times 10^{1} & -1.19 \times 10^{1} & 4.21 \times 10^{-1} \\
0 & 0 & 0 & -1.19 \times 10^{1} & 3.15 \times 10^{1} & -3.87 \times 10^{-1} \\
0 & 0 & 0 & 4.21 \times 10^{-1} & -3.87 \times 10^{-1} & 5.54 \times 10^{1}
\end{array}\right]} \\
& {[S]_{\text {case } 2}=\left[\begin{array}{cccccc}
2.91 \times 10^{6} & 8.94 \times 10^{2} & 2.83 \times 10^{5} & 0 & 0 & 0 \\
8.94 \times 10^{2} & 3.07 \times 10^{5} & 9.15 \times 10^{2} & 0 & 0 & 0 \\
2.83 \times 10^{5} & 9.15 \times 10^{2} & 1.59 \times 10^{5} & 0 & 0 & 0 \\
0 & 0 & 0 & 1.36 \times 10^{1} & 4.90 \times 10^{-1} & -1.22 \times 10^{1} \\
0 & 0 & 0 & 4.90 \times 10^{-1} & 3.40 \times 10^{1} & -4.30 \times 10^{-1} \\
0 & 0 & 0 & -1.22 \times 10^{1} & -4.30 \times 10^{-1} & 5.35 \times 10^{1}
\end{array}\right]} \\
& {[S]_{\text {case } 3}=\left[\begin{array}{cccccc}
3.09 \times 10^{6} & 0 & 0 & -4.54 \times 10^{3} & 0 & 0 \\
0 & 1.34 \times 10^{5} & 0 & 0 & 1.12 \times 10^{3} & 0 \\
0 & 0 & 7.58 \times 10^{4} & 0 & 0 & 1.10 \times 10^{3} \\
-4.54 \times 10^{3} & 0 & 0 & 1.23 \times 10^{1} & 0 & 0 \\
0 & 1.12 \times 10^{3} & 0 & 0 & 2.69 \times 10^{1} & 0 \\
0 & 0 & 1.10 \times 10^{3} & 0 & 0 & 4.78 \times 10^{1}
\end{array}\right]}
\end{aligned}
$$


The blade is equipped with curved blade tip devices in both the in-plane and out-of-plane directions. Figure 3 shows the blade shapes for different curved tip segment lengths when the tip is curved towards the in-plane with $k_{3}=0.1 / \mathrm{m}$. Furthermore, Figure 4 shows the shape of the blade tip for various tip initial curvatures when the length of the tip is $25 \%$ of the blade $(d l=25 \%)$. In what follows, the effect of curvature of the blade tip on the rotating frequencies of the composite blade is investigated.

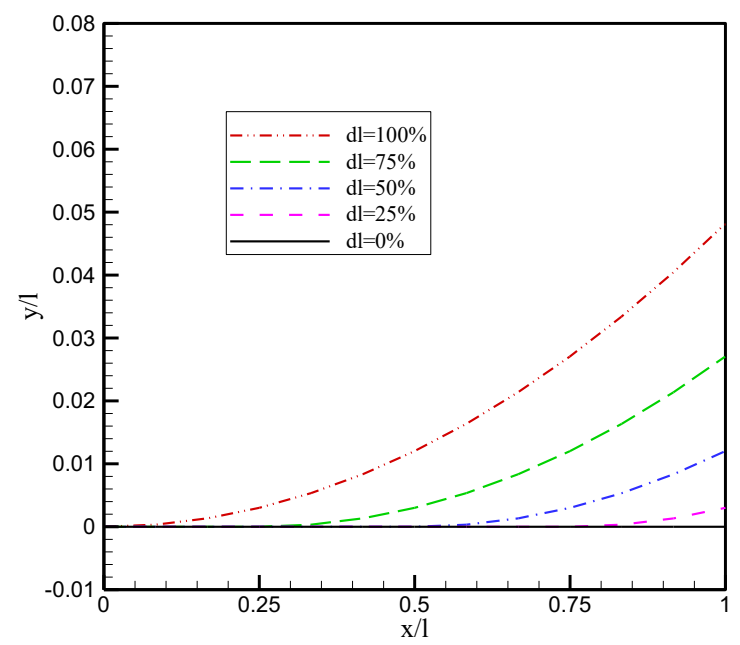

Figure 3: Blade configuration when different percentages of the blade is curved for $k_{3}=0.1$

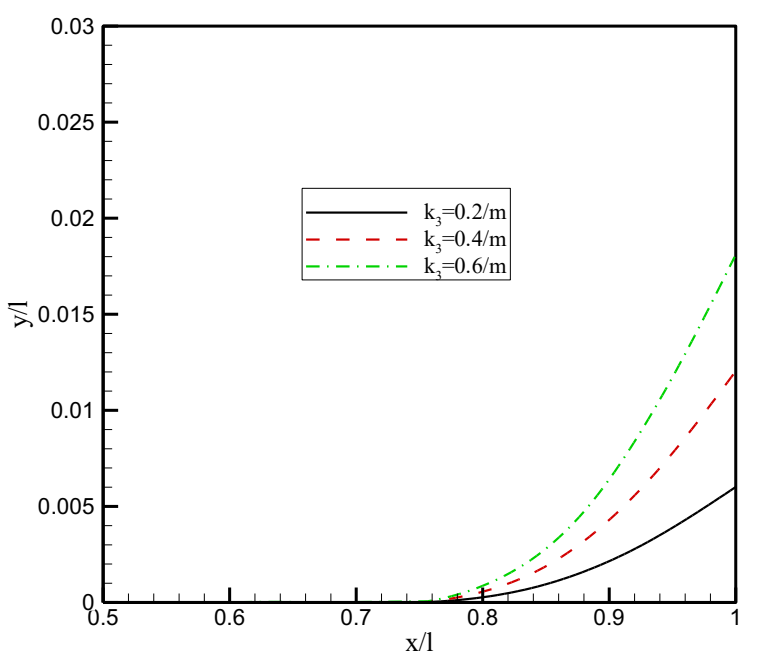

Figure 4: Swept tip configuration for various curvature values when $25 \%$ of the span from the tip is curved $(d l=25 \%)$

\subsection{Effect of layup on the composite straight blade rotating frequencies}

In order to isolate the effect of ply angle from blade curvature, the effect of ply angle of the three layup cases shown in Table 5 on the rotating frequencies of the straight blade are determined and shown in Figure 5-7. All of the first five frequencies are dependent on the ply angle of the composite box, but the trend is different for different layups. The first lag and the first flap modes do not change significantly with ply angle in all layups, but the other 
modes change to some extent. In the first layup (F-T), Figure 5 shows that the second lag mode gradually decreases as the ply angle is increased, while the first torsion and second flap modes approach each other until $\zeta \approx 15^{\circ}$, and then after this point veer away from each other. Mode veering happens when two modes approach each other and then instead of crossing, they veer away from each other [36]. This veering phenomena happens mostly due to the existence of couplings in the system. Then, they again approach to become close again. This is mainly due to the existence of elastic flap-torsion coupling in this layup.

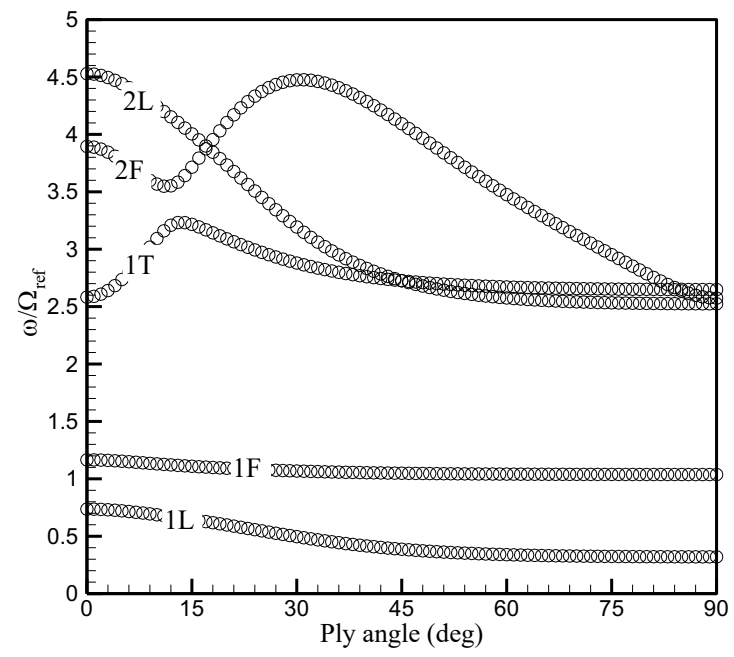

Figure 5: Effect of ply angle on the rotating frequencies of the composite blade with the layup of case1

For the second layup (L-T), as shown in Figure 6, for this specific blade, the first torsion and the second lag modes move towards each other, and then veer, and finally again approach to a specific point. This is mainly because of the lag-torsion coupling that exists in this case. In this case, the second flap mode gradually decreases until reaching a specific point which almost coincides with the third and fourth frequencies.

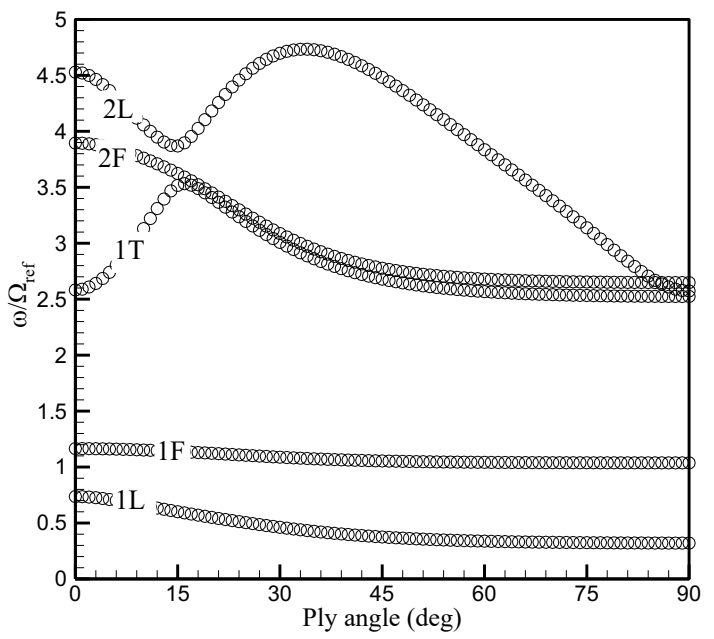

Figure 6: Effect of ply angle on the rotating frequencies of the composite blade with the layup of case2 
For the third layup (E-T), in which the extension-twist coupling is dominant, the second flap mode decreases, but the first torsion and the second lag modes first approach together and then veer away from each other (Figure 7).

It is noted that in this case, the veering area is smaller than the previous cases.

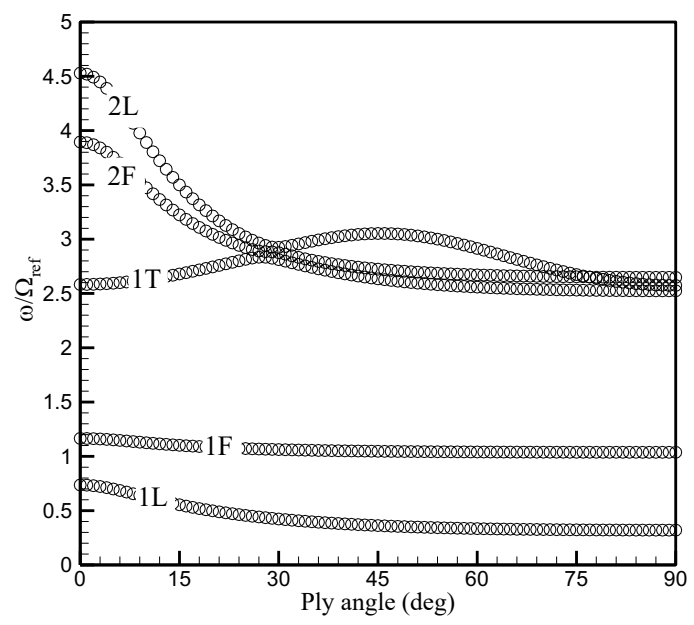

Figure 7: Effect of ply angle on the rotating frequencies of the composite blade with the layup of case 3

Finally, the effect of rotor angular velocity on the composite blade frequencies for these three cases are obtained and shown in Figure 8. The difference between the frequencies of the first lag and the first flap modes for case 2 (L-T) is smaller than the other two cases, and the biggest difference is for the first case (F-T). This results in different angular velocities at which the two first modes cross each other. Furthermore, in higher modes, for the first layup, they are the second flap and the second lag modes that cross/veer, but for the second and third layups, the first torsion and the second flap modes cross/veer. Moreover, the angular velocity at which the modes cross/veer is different for these three cases.

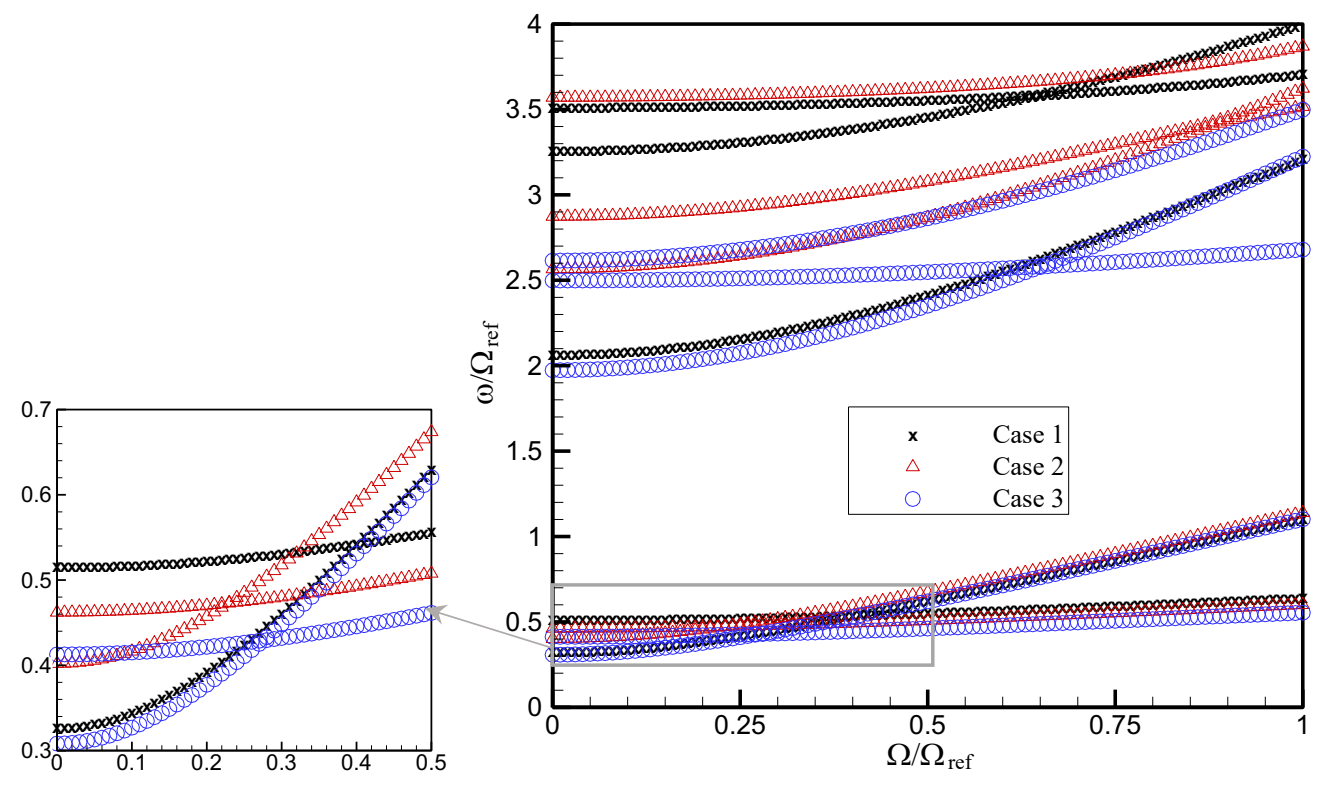

Figure 8: The fan plot of the composite blade with three different layups for $\zeta=15^{\circ}$ 


\section{2}

Effect of in-plane and out-of-plane curved tips on the blade equilibrium deflection

The steady-state static equilibrium conditions of the blade for all three layup cases are determined and shown in Figure 9-11. It is assumed that the curved tip length is $\mathrm{dl}=40 \%$ and the layup angle is $\zeta=15^{\circ}$. It is noted that here all static deflection values are obtained with respect to the reference deflections of the straight blade without any tips. Therefore, the values shown here are the differences between the deflection of the blade with and without tips. Figure 9 shows the effect of curved tip on the change of tip lag deflection. It is clear that when the curved tip is added to the blade, the lag deflection of the blade changes, but these changes are small. The highest values of lag deflection for all three layups belong to the cases when the blade has an in-plane curved tip.

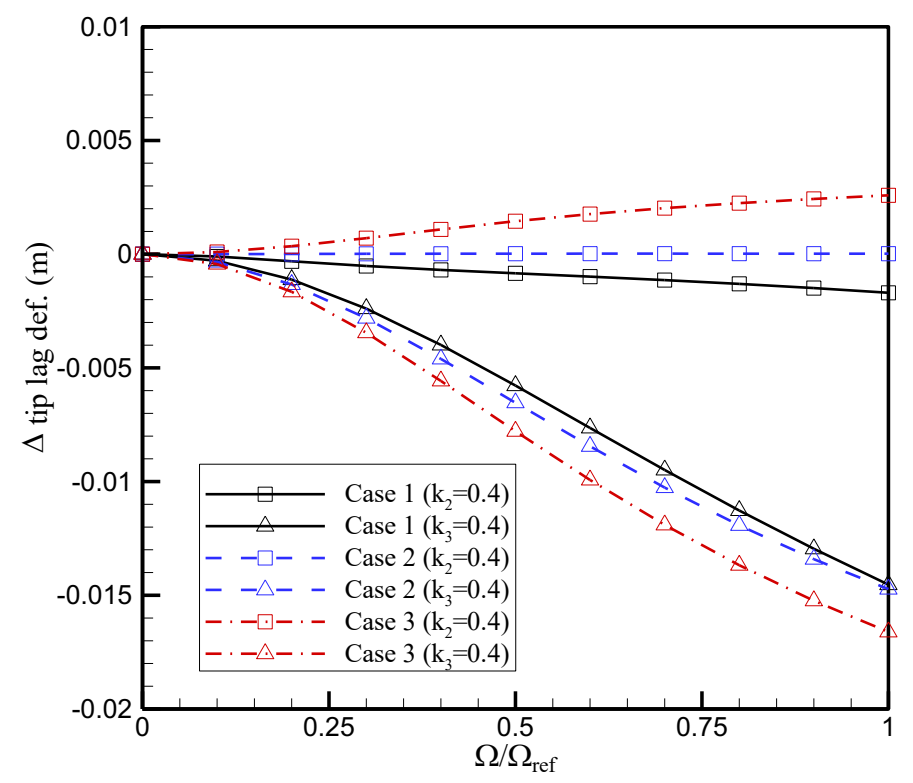

Figure 9: Effect of rotating speed on the change in blade tip lag deflection for $\zeta=15$ and $\mathrm{dl}=40 \%$

The effect of rotating speed on the tip flap deflection is shown in Figure 10. For all three layups, when the blade has an in-plane curved tip the flap deflection doesn't change significantly, but when it is equipped with out-ofplane curved tips, the flap deflection of the blade changes. 


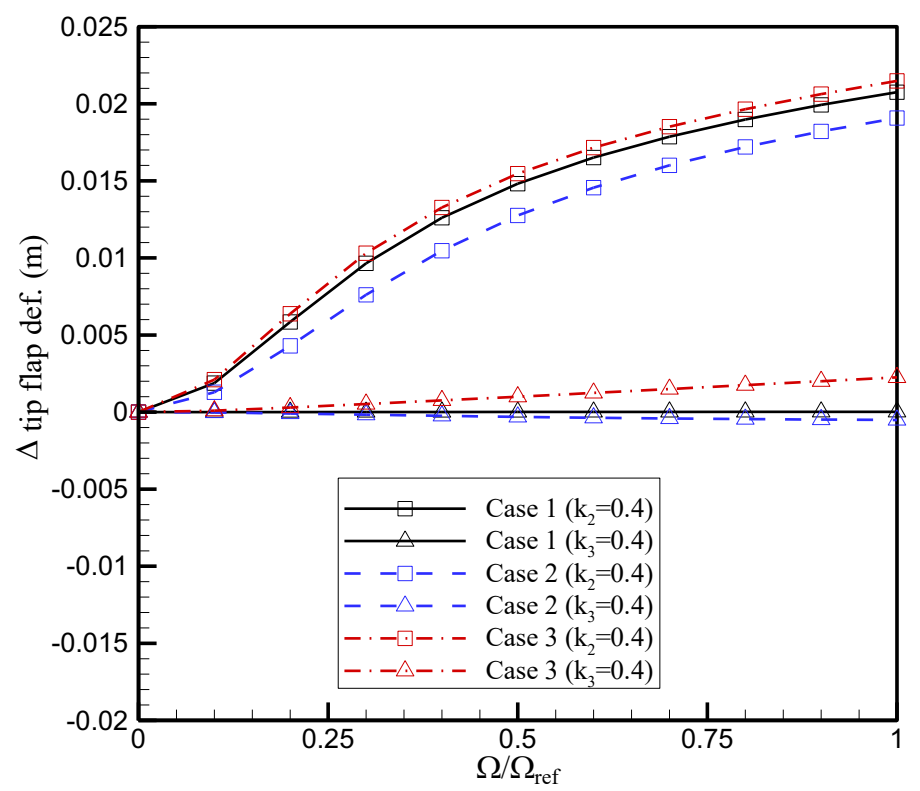

Figure 10: Effect of rotating speed on the change in blade tip flap deflection for $\zeta=15$ and $\mathrm{dl}=40 \%$

Figure 11 shows the change of elastic tip twist of the blade when the blade has a curved tip. Here, for the third layup case, when the extension-twist coupling is dominant, by adding the curved tip to the blade, the twist value remains almost unchanged. The highest value of twist change occurs for the first layup case and when the blade tip has out-of-plane curvature. Also, for the second layup, the out-of-plane curved tip affects the twist distribution of the blade. It is noted that all the values of elastic deflections depend on the rotating speed value.

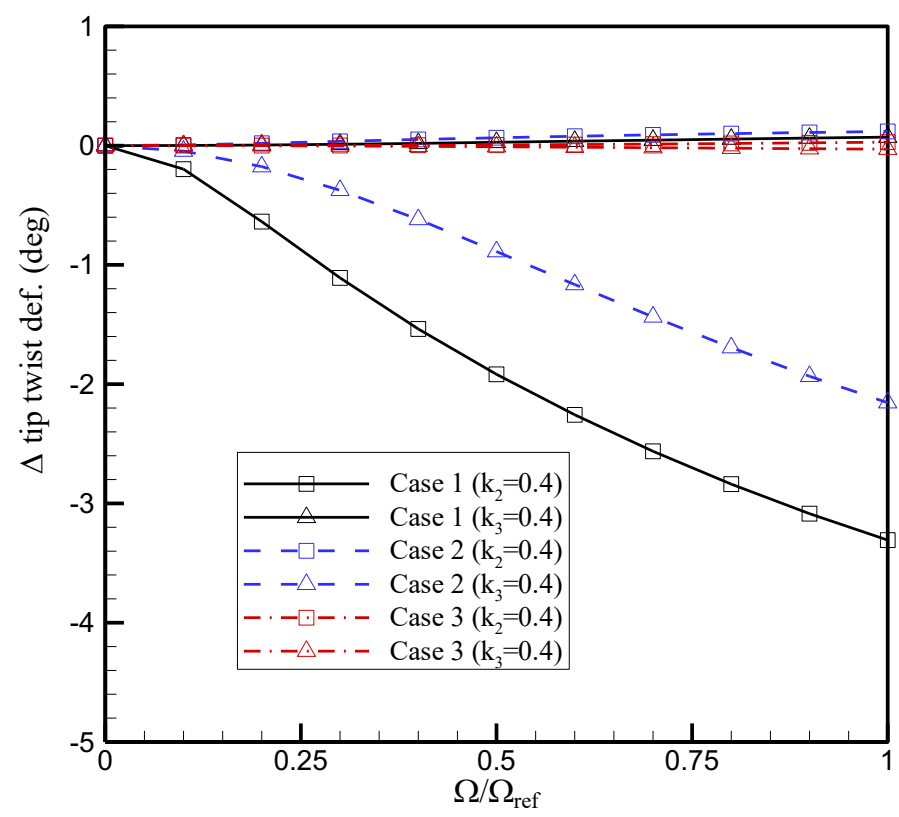

Figure 11: Effect of rotating speed on the change in blade tip elastic twist for $\zeta=15$ and $\mathrm{dl}=40 \%$ 


\subsection{Effect of an in-plane curved tip on the blade rotating frequencies}

In this section the effect of an in-plane curved tip on the dynamics of the blade is investigated. The in-plane tip resembles the swept backward or forward tip, but the tip has a constant initial curvature. Therefore, the effect of this continuous curvature on the dynamics of the composite blade is considered here. First the effect of different initial curvatures on the dynamics of the blade when the ply angle is $\zeta=0^{\circ}$ is determined and shown in Figure 12. This case is selected first to check what happens to the blade dynamics when there is no extra elastic coupling that occurs in the stiffness matrix due to the composite layups presented in Table 5 . In this case, $40 \%$ of the blade from the tip is curved $(\mathrm{dl}=40 \%)$. The in-plane curved tip doesn't affect the frequency values of the first lag, the first flap and the second lag modes significantly. Furthermore, when the curvature increases, the first torsion mode frequency decreases, but the rate of change is different for different angular velocities. For the second flap mode, by increasing the initial curvature of the tip, the rotating frequency increases.

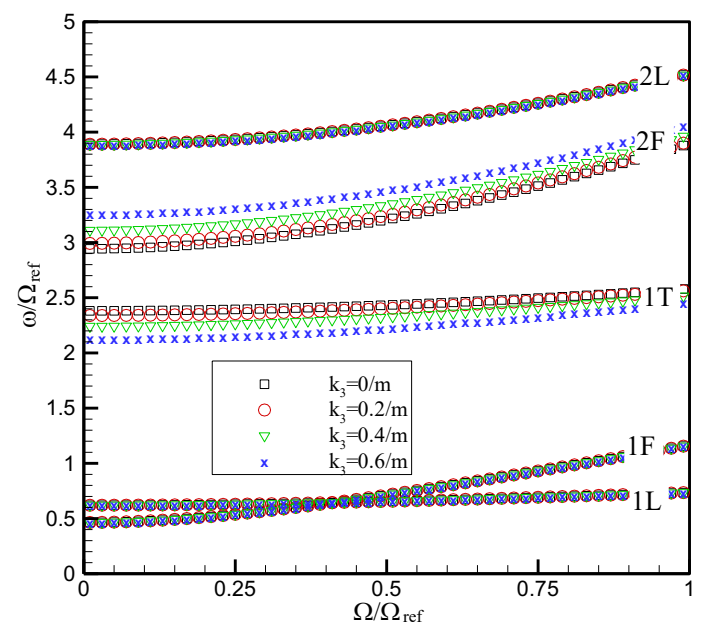

Figure 12: Effect of in-plane tip curvature on the rotating frequencies of the blade for $\zeta=0^{\circ}$ and $\mathrm{dl}=40 \%$

Figure 13 shows the changes of torsion $\left(\Phi_{M_{1}}\right)$, flap $\left(\Phi_{M_{2}}\right)$ and lag $\left(\Phi_{M_{3}}\right)$ eigenvectors of the modes with and without in-plane curvature. It is noted that the modes have been normalised so that the 2-norm of each mode is equal to 1 . In this case, the ply angle of the blade is $\zeta=0^{\circ}$, and $40 \%$ of the blade from the tip is curved. It is clear that the addition of the in-plane curvature to the tip of the blade adds an extra flap-torsion coupling that influences the dynamics of an equivalent isotropic blade. 
a)
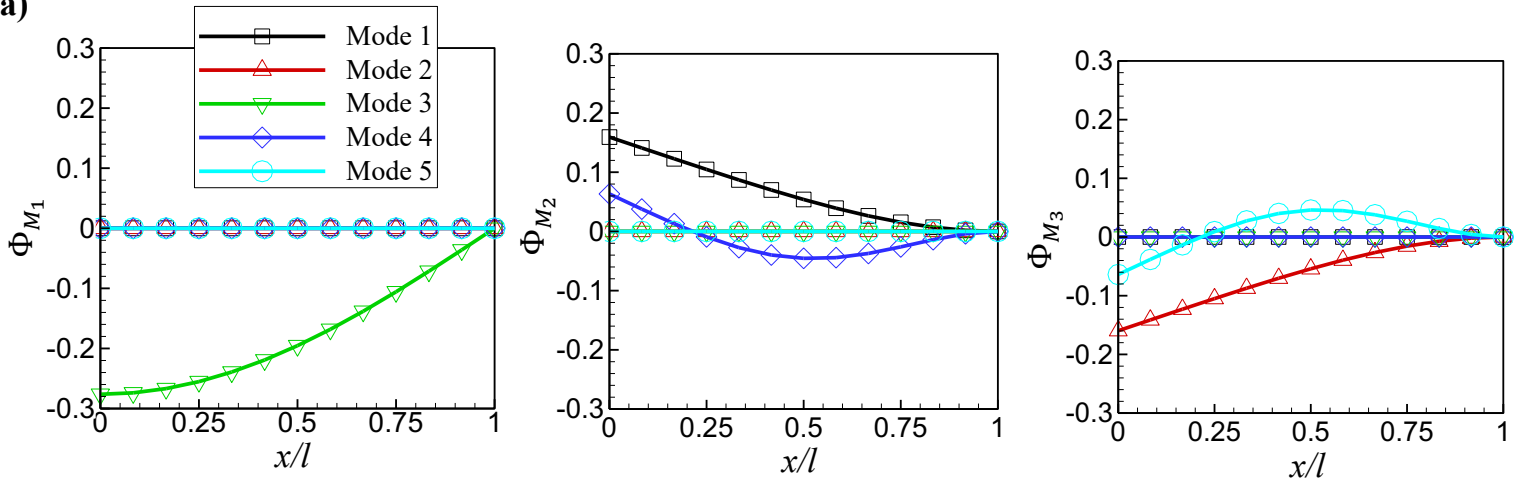

b)
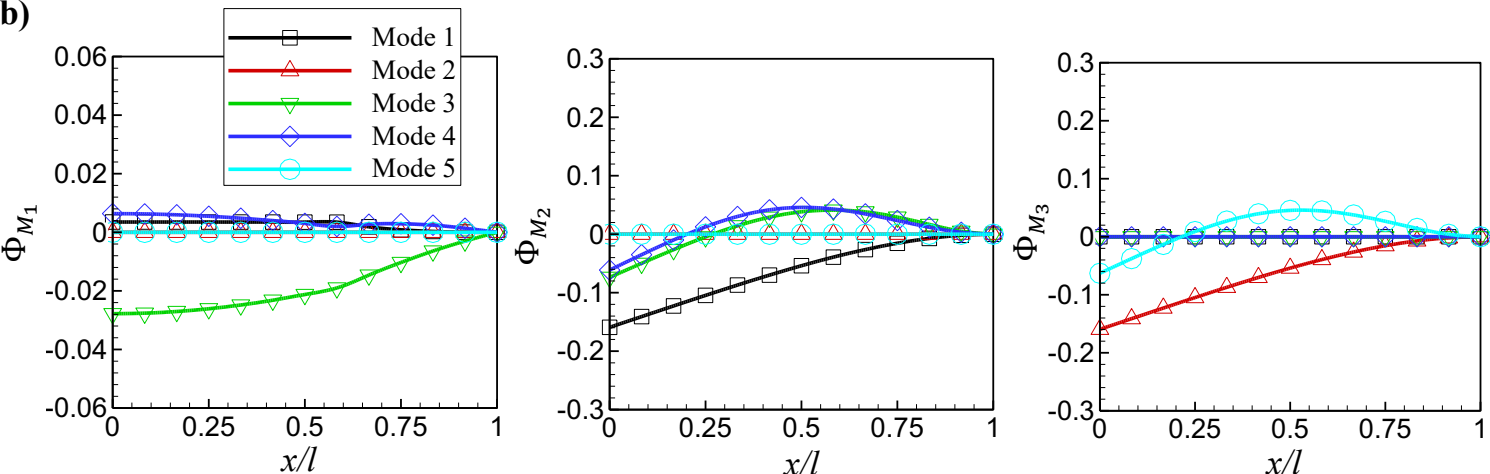

Figure 13: The mode shapes of the blade for $\zeta=0^{\circ}$ a) straight blade b) $\mathrm{k}_{3}=0.6 / \mathrm{m}$ and $\mathrm{dl}=40 \%$

The same equivalent isotropic blade $\left(\zeta=0^{\circ}\right)$ is considered again, and the effect of tip length and initial curvature on the rotating frequencies of the blade is obtained and shown in Figure 14. The first lag, the first flap, and the second lag modes are less insensitive to the change of tip length and curvature. But, the first torsion and second flap modes are highly sensitive to both length and curvature of the in-plane tip. When the length and curvature of the tip segment increases, the first torsion mode decreases, while the second flap mode increases.



Figure 14: Effect of in-plane tip curvature and $\mathrm{dl}$ on the rotating frequencies of the blade for $\zeta=0^{\circ}$ and $\Omega_{\mathrm{ref}}=1000 \mathrm{rpm}$

Next, the three composite layup cases prescribed earlier are considered, and the effect of an in-plane curved tip on the dynamics of the blade is investigated. As shown above, the in-plane curved tip can induce an additional 
flap-torsion coupling and the interaction of this coupling combined with the other coupling from the composite lamination can affect the dynamics of the blade. Figure 15 shows the mutual effects of ply angle and initial curvature on the rotating frequencies of the blade with the layup of case 1 . In this layup, the direction of the initial curvatures (forward or backward) also affects the frequencies of the blade. The domain of ply angles at which the curvature of the tip influences the first torsion and the second flap frequencies lies between $0^{\circ} \leq \zeta \leq 40^{\circ}$. Outside this domain, these two frequencies do not change significantly. Moreover, the initial curvature of the tip, depending on the ply angle, can increase or decrease the rotating frequency of the blade.

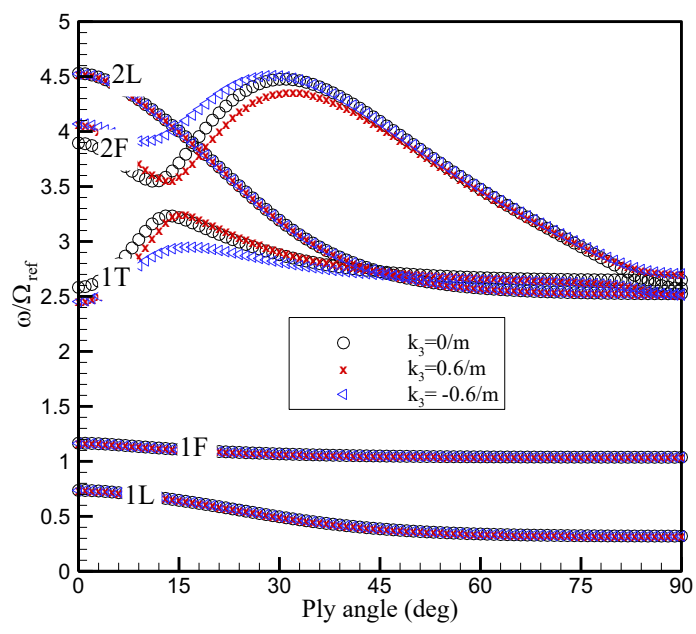

Figure 15: Effect of ply angle on the rotating frequencies of the composite blade with in-plane curved tip for case1 and

$$
\mathrm{dl}=40 \%
$$

The effect of tip curvature on the rotating frequencies of the blade with the layup of case 2 is shown in Figure 16. In this case, when the blade is straight, the second flap mode gradually decreases by increasing the ply angle, but when the curved tip is added to the blade, this mode veers away from the second lag mode at around $\zeta=10^{\circ}$. It is noted that the range of ply angles where the curved tip affects the frequencies of the blade shrinks with respect to case 1.

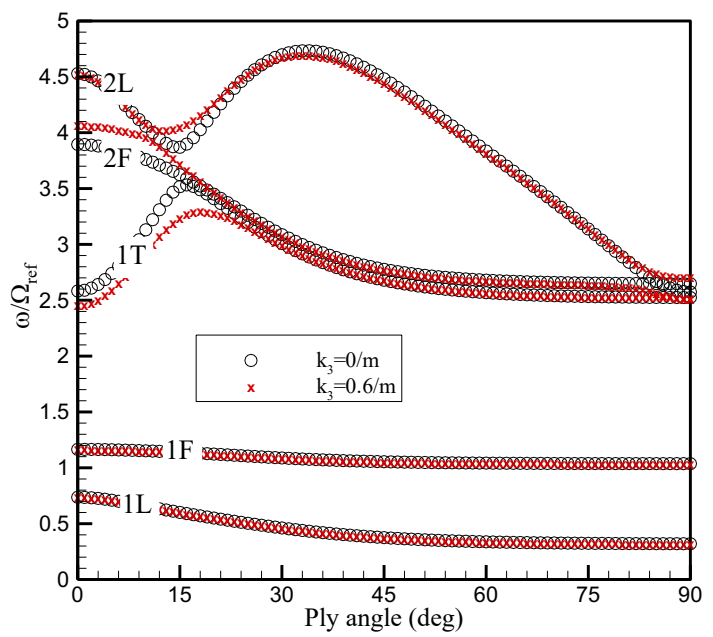


Figure 16: Effect of ply angle on the rotating frequencies of the composite blade with in-plane curved tip for case2 and

$$
\mathrm{dl}=40 \%
$$

The effect of tip in-plane curvature on the rotating frequencies of the blade for case 3 is determined and shown in Figure 17. In this case, the curvature of the tip affects all three higher modes to some extent, but the domain of influence is different for different modes.

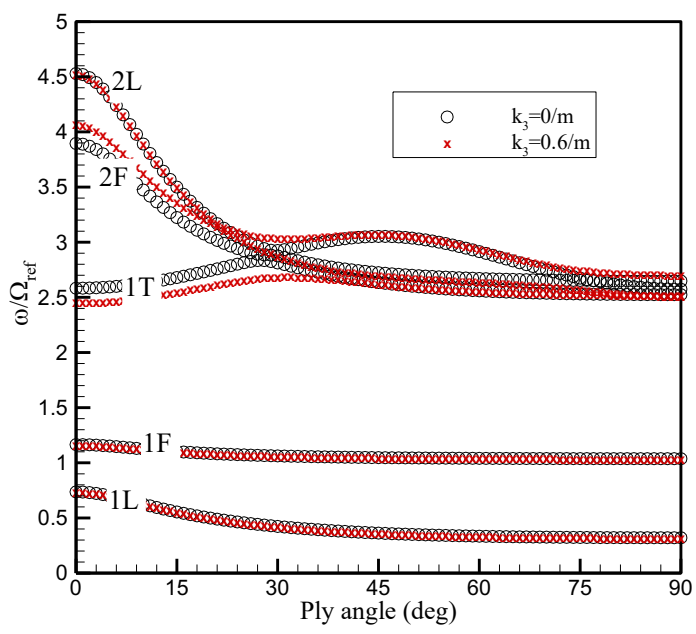

Figure 17: Effect of ply angle on the rotating frequencies of the composite blade with in-plane curved tip for case 3 and

$$
\mathrm{dl}=40 \%
$$

\subsection{Effect of an out-of-plane curved tip on the blade rotating frequencies}

The other option for the blade tip is that it has a dihedral/anhedral angle with respect to the blade. In this section, the blade is assumed to have a curved out-of-plane tip, and the effect of the curvature and length of the tip on the dynamics of the blade is investigated. Figure 18 shows the effect of different initial curvatures on the dynamics of the blade when the ply angle is $\zeta=0^{\circ}$. In this case, again $40 \%$ of the blade from the tip is curved. The out-ofplane curved tip doesn't affect the frequency of the first lag, the first flap and the second flap modes significantly. Furthermore, when the curvature increases, the first torsion mode frequency value decreases, but the rate of change is different for different angular velocities. For the second lag mode, by increasing the initial curvature of the tip, the rotating frequency increases. 


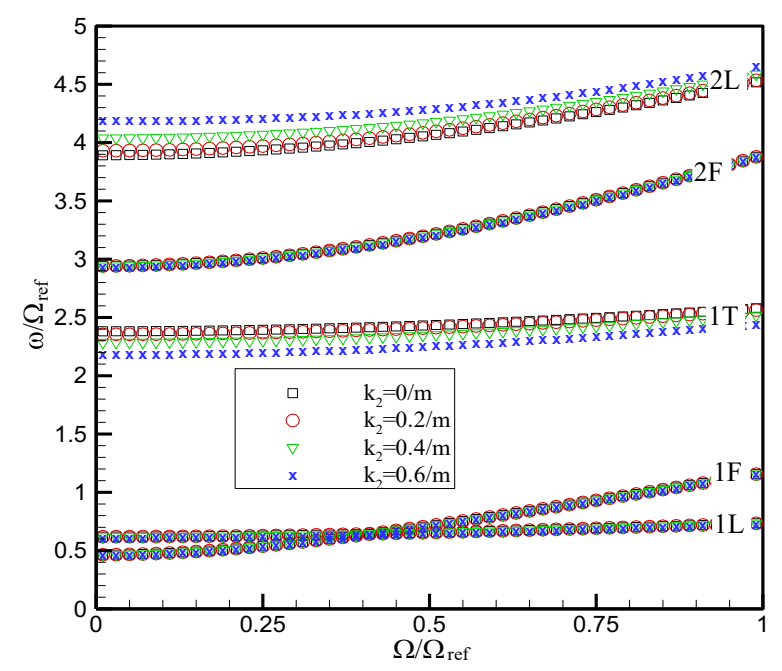

Figure 18: Effect of out-of-plane tip curvature on the rotating frequencies of the blade for $\zeta=0^{\circ}$ and $\mathrm{dl}=40 \%$

Figure 19 shows the variation of torsion $\left(\Phi_{M_{1}}\right)$, flap $\left(\Phi_{M_{2}}\right)$ and lag $\left(\Phi_{M_{3}}\right)$ eigenvectors of the modes for the blade with and without out-of-plane curvature. In this case, the ply angle of the blade is $\zeta=0^{\circ}$, and $40 \%$ of the blade from the tip is curved. This clarifies that the out-of-plane curvature of the tip induces an additional lag-torsion coupling to the rotating blade.

a)
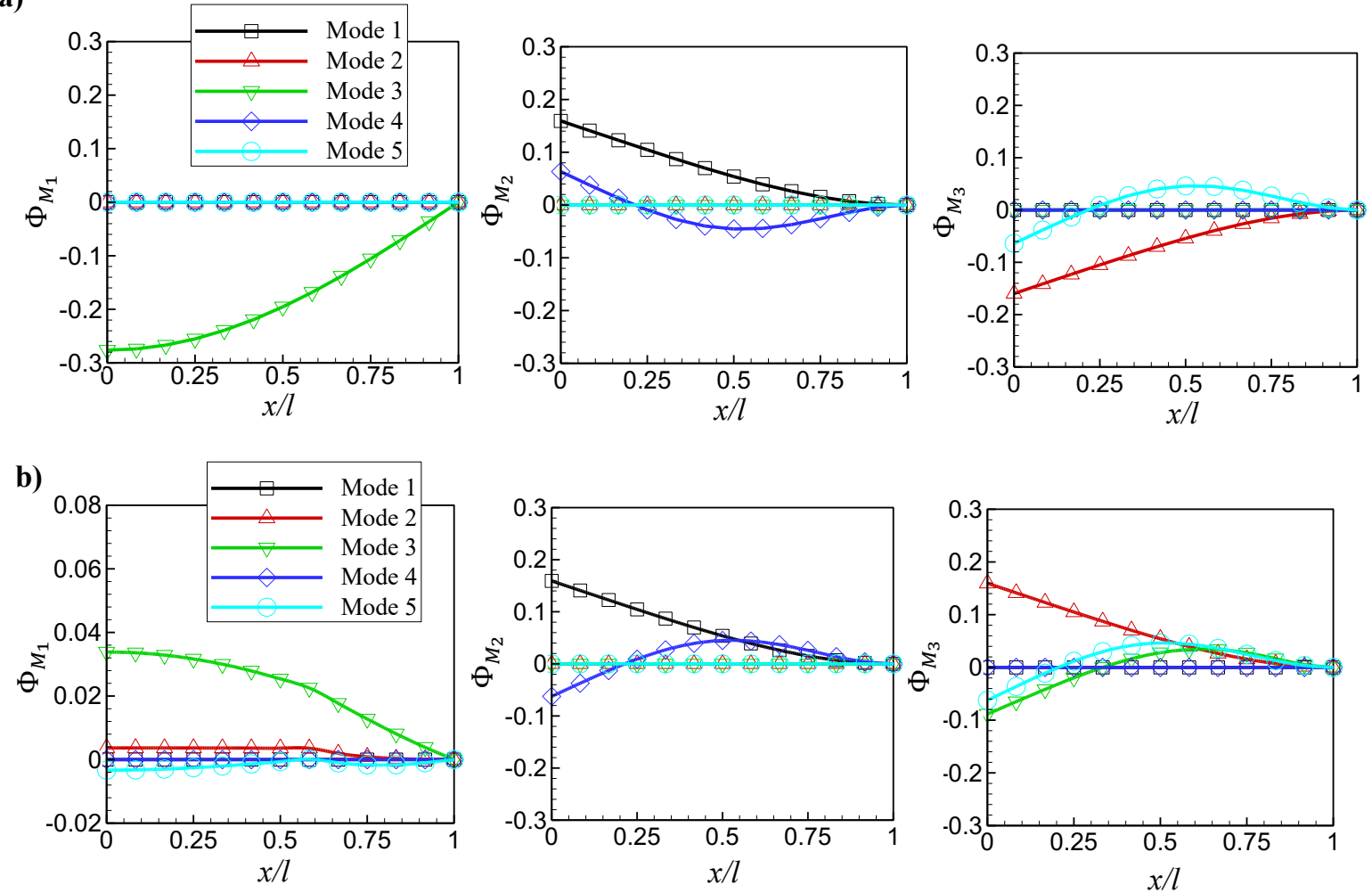

Figure 19: The mode shapes of the blade for $\zeta=0^{\circ}$ a) straight blade b) $\mathrm{k}_{2}=0.6 / \mathrm{m}$ and $\mathrm{dl}=40 \%$

The effect of an out-of-plane curved tip on the dynamics of the blade for three specified cases are investigated next and shown in Figures 20-22. Figure 20 shows the effects of ply angle and initial curvature on the rotating 
frequencies for case 1. In this case, when there is no blade tip, the second lag mode gradually decreases by increasing of ply angle, but when the curved tip is added to the blade, this changes. It is noted that the range of ply angles where the curved tip affects the frequencies of the blade is $0^{\circ} \leq \zeta \leq 30^{\circ}$.

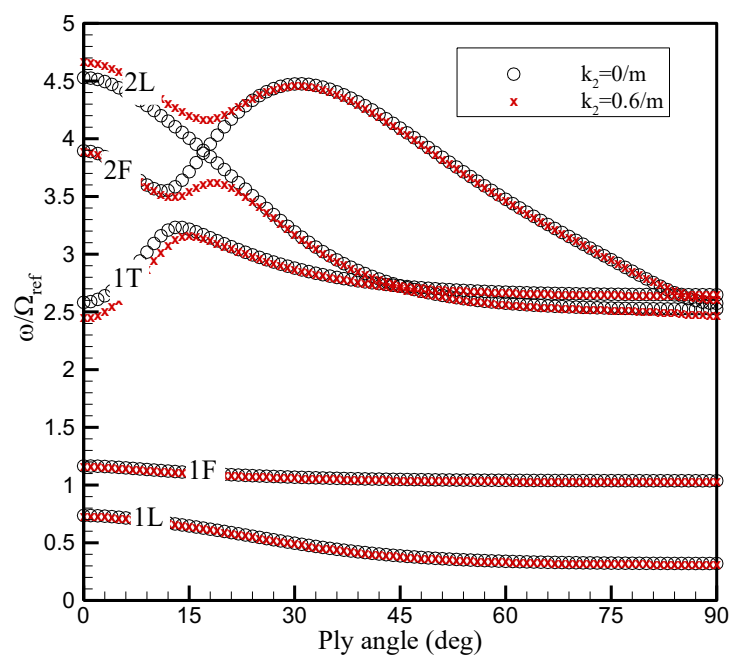

Figure 20: Effect of ply angle on the rotating frequencies of the composite blade with out-of-plane curved tip for case 1 and $\mathrm{dl}=40 \%$

Figure 21 shows the effect of the out-of-plane curvature angle on the rotating frequencies for the case 2 blade for various ply angles. In this layup, the direction of the initial curvatures (upward or downward) also affects the frequencies of the blade. The domain of ply angles at which the curvature of the tip influences the first torsion and the second lag frequencies lies between $0^{\circ} \leq \zeta \leq 40^{\circ}$. Outside this domain, these two frequencies do not change significantly.

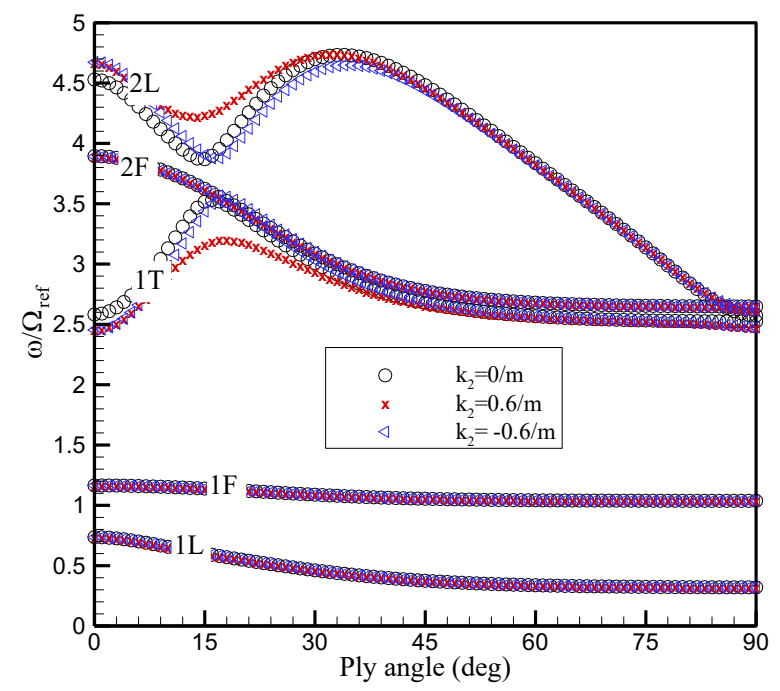


Figure 21: Effect of ply angle on the rotating frequencies of the composite blade with an out-of-plane curved tip for case 2

$$
\text { and } \mathrm{dl}=40 \%
$$

The effect of a tip out-of-plane curvature on the rotating frequencies for the case 3 blade is determined and shown in Figure 22. In this case, the curvature of the tip affects the first torsion and the second lag modes slightly, but doesn't influence the second flap mode.

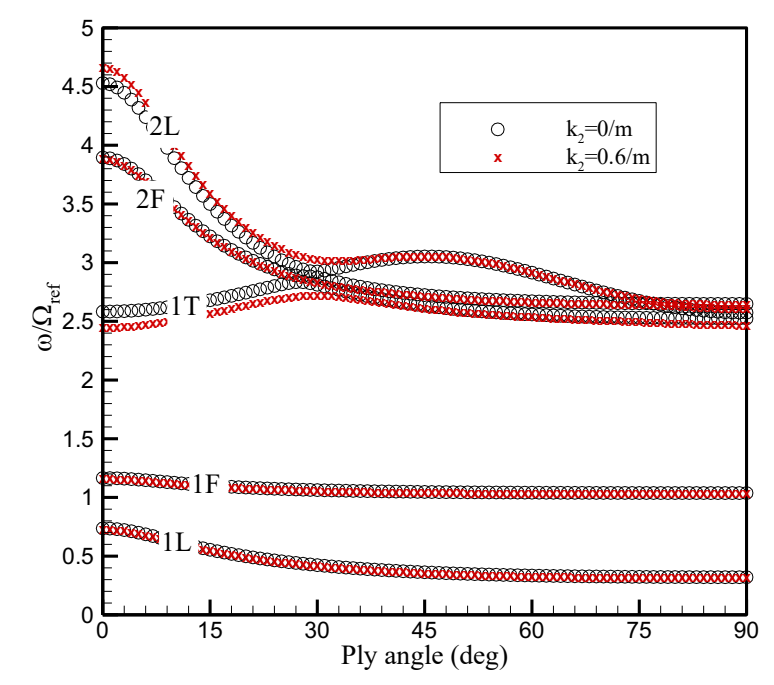

Figure 22: Effect of ply angle on the rotating frequencies of the composite blade with out-of-plane curved tip for case 3 and

$$
\mathrm{dl}=40 \%
$$

Finally it must be noted that when the tip of the blade has both in-plane and out-of-plane curvatures at the same time, the resulting system has both flap-torsion and lag-torsion couplings and hence different dynamic behaviour for various layups.

\section{Conclusion}

In this paper, the dynamics of a rotating composite blade equipped with curved tip devices has been considered. The general idea is to change the tip of the blade in flight by a proper mechanism which in turn can alter the dynamic behaviour of the blade. The composite blade is simulated by using the geometrically exact beam formulation, and the cross-sectional properties of the blade are calculated through the variational asymptotic approach. It is assumed that the tip of the blade is curved in two different directions so that the tip can morph its shape in the in-plane or out-of-plan directions. Three composite cases have been considered; each of them represents one of the main elastic couplings that might exist in a composite blade which can affect the aeroelastic properties of the blade. These are the flap-twist, lag-twist, and extension-twist couplings. To estimate the rotating frequencies of the blade, first the nonlinear steady-state response is obtained, and then the eigenvalues of the linearized system are determined. In the first step, the results have been compared with those published in the 
literature and the validity of the developed procedure was checked. Then the effects of the composite lamination and ply angles along with the curvature of the blade tip on the rotating frequencies have been investigated. It has been shown for a blade equipped with an in-plane curved tip, an additional flap-torsion coupling can be introduced to the isotropic blade, while for the out-of-plane curved tip, the lag-torsion coupling is the source of change in the dynamics of the isotropic blade. Furthermore, it has been shown that increasing the tip length and tip curvature have different impacts on different modes and also different cases. Depending on the type of the lamination and the type of elastic coupling coming from different laminations, the rotating frequencies of the blade are affected by the in-plane or the out-of-plane curvatures. This paper is an initial study to show the potential of using curved tips for tuning the blade natural frequencies. In future study this will be validated experimentally and extended by using variable curved tips for helicopter morphing applications.

\section{Acknowledgments}

The work presented in this paper was funded by the European Community's Horizon 2020 Program through the project "Shape Adaptive Blades for Rotorcraft Efficiency (SABRE)", Grant Agreement 723491.

\section{References}

1. Vouros, S., Goulos, I., and Pachidis, V. "Integrated methodology for the prediction of helicopter rotor noise at mission level," Aerospace Science and Technology Vol. 89, 2019, pp. 136-149.

2. Romani, G., and Casalino, D. "Rotorcraft blade-vortex interaction noise prediction using the LatticeBoltzmann method," Aerospace Science and Technology Vol. 88, 2019, pp. 147-157.

3. Friedmann, P. P., and Hodges, D. H. "Rotary Wing Aeroelasticity-A Historical Perspective," Journal of Aircraft Vol. 40, No. 6, 2003, pp. 1019-1046.

4. Tamer, A., Muscarello, V., Masarati, P., and Quaranta, G. "Evaluation of vibration reduction devices for helicopter ride quality improvement," Aerospace Science and Technology Vol. 95, 2019, p. 105456.

5. Dibble, R., Ondra, V., and Titurus, B. "Resonance avoidance for variable speed rotor blades using an applied compressive load," Aerospace Science and Technology Vol. 88, 2019, pp. 222-232.

6. Rohin Kumar, M., and Venkatesan, C. "Effects of rotor blade-tip geometry on helicopter trim and control response," The Aeronautical Journal Vol. 121, No. 1239, 2017, pp. 637-659.

7. Shang, X., Hodges, D. H., and Peters, D. A. "Aeroelastic Stability of Composite Hingeless Rotors in Hover with Finite-State Unsteady Aerodynamics," Journal of the American Helicopter Society Vol. 44, No. 3, 1999, pp. 206-221. 
8. Tarzanin, F. J. J., and Vlaminck, R. R. "Investigation of the effect of blade sweep on rotor vibratory loads," NASA CR-166526, 1983.

9. Celi, R., and Friedmann, P. Y. "Aeroelastic Modeling of Swept Tip Rotor Blades Using Finite Elements," Journal of the American Helicopter Society Vol. 33, No. 2, 1988, pp. 43-52.

10. Panda, B. "Technical Note: Assembly of Moderate-Rotation Finite Elements Used in Helicopter Rotor Dynamics," Journal of the American Helicopter Society Vol. 32, No. 4, 1987, pp. 63-69.

11. Benquet, P., and Chopra, I. "Calculated dynamic response and loads for an advanced tip rotor in forward flight," Proc. 15th European Rotorcraft Forum, Amsterdam 1989, pp. 50.1-50.25.

12. Kim, K., Chung, and Chopra, I. "Aeroelastic Analysis of Swept, Anhedral, and Tapered Tip Rotor Blades," Journal of the American Helicopter Society Vol. 37, No. 1, 1992, pp. 15-30.

13. Yuan, K.-A., Friedmann, P., and Venkatesan, C. "A new aeroelastic model for composite rotor blades with straight andswept tips," 33rd Structures, Structural Dynamics and Materials Conference. American Institute of Aeronautics and Astronautics, 1992.

14. Friedmann, P. P., Yuan, K.-A., and de Terlizzi, M. "An aeroelastic model for composite rotor blades with straight and swept tips. Part I: Aeroelastic stability in hover," International Journal of Non-Linear Mechanics Vol. 37, No. 4, 2002, pp. 967-986.

15. Brocklehurst, A., and Barakos, G. N. "A review of helicopter rotor blade tip shapes," Progress in Aerospace Sciences Vol. 56, 2013, pp. 35-74.

16. Zhu, Z., and Zhao, Q.-j. "Optimization for rotor blade-tip planform with low high-speed impulsive noise characteristics in forward flight," Proceedings of the Institution of Mechanical Engineers, Part G: Journal of Aerospace Engineering Vol. 231, No. 7, 2017, pp. 1312-1324.

17. Filippi, M., Zappino, E., and Carrera, E. "Multidimensional Models for Double-Swept Helicopter Blades," AIAA Journal Vol. 57, No. 6, 2019, pp. 2609-2616.

18. Chen, P. C., and Chopra, I. "Induced strain actuation of composite beams and rotor blades with embedded piezoceramic elements," Smart Materials and Structures Vol. 5, No. 1, 1996, p. 35.

19. Chen, P. C., and Chopra, I. "Hover Testing of Smart Rotor with Induced-Strain Actuation of Blade Twist," AIAA Journal Vol. 35, No. 1, 1997, pp. 6-16.

20. Prahlad, H., and Chopra, I. "Design of a variable twist tilt-rotor blade using shape memory alloy (SMA) actuators," SPIE's 8th Annual International Symposium on Smart Structures and Materials, 2001.

21. Mistry, M., Gandhi, F., Nagelsmit, M., and Gurdal, Z. "Actuation Requirements of a Warp-Induced Variable Twist Rotor Blade," Journal of Intelligent Material Systems and Structures Vol. 22, No. 9, 2011, pp. 919-933. 
22. Barbarino, S., Gandhi, F., and Webster, S. D. "Design of Extendable Chord Sections for Morphing Helicopter Rotor Blades," Journal of Intelligent Material Systems and Structures Vol. 22, No. 9, 2011, pp. 891-905.

23. Moser, P., Barbarino, S., and Gandhi, F. "Helicopter Rotor-Blade Chord Extension Morphing Using a Centrifugally Actuated Von Mises Truss," AIAA Journal Vol. 51, No. 5, 2014, pp. 1422-1431.

24. Rivero, A. E., Weaver, P. M., Cooper, J. E., and Woods, B. K. "Parametric structural modelling of fish bone active camber morphing aerofoils," Journal of Intelligent Material Systems and Structures Vol. 29, No. 9, 2018, pp. 2008-2026.

25. Woods, B. K. S., and Friswell, M. I. "Preliminary Investigation of a Fishbone Active Camber Concept," No. 45103, 2012, pp. 555-563.

26. Amoozgar, M. R., Shaw, A. D., Zhang, J., and Friswell, M. I. "The effect of a movable mass on the aeroelastic stability of composite hingeless rotor blades in hover," Journal of Fluids and Structures Vol. 87, 2019, pp. 124-136.

27. Amoozgar, M. R., Shaw, A. D., Zhang, J., and Friswell, M. I. "Composite Blade Twist Modification by Using a Moving Mass and Stiffness Tailoring," AIAA Journal Vol. 57, No. 10, 2019, pp. 4218-4225.

28. Hodges, D. H. "Geometrically Exact, Intrinsic Theory for Dynamics of Curved and Twisted Anisotropic Beams," AIAA Journal Vol. 41, No. 6, 2003, pp. 1131-1137.

29. Amoozgar, M. R., and Shahverdi, H. "Aeroelastic Stability Analysis of Curved Composite Blades in Hover Using Fully Intrinsic Equations," International Journal of Aeronautical and Space Sciences, 2019.

30. Amoozgar, M. R., Shaw, A. D., Zhang, J., Wang, C., and Friswell, M. I. "Lag-twist coupling sensitivity and design for a composite blade cross-section with D-spar," Aerospace Science and Technology Vol. 91, 2019, pp. 539-547.

31. Fulton, M. V., and Hodges, D. H. "Aeroelastic stability of composite hingeless rotor blades in hoverPart II: Results," Mathematical and Computer Modelling Vol. 18, No. 3, 1993, pp. 19-35.

32. Mardanpour, P., Hodges, D. H., Neuhart, R., and Graybeal, N. "Engine Placement Effect on Nonlinear Trim and Stability of Flying Wing Aircraft," Journal of Aircraft Vol. 50, No. 6, 2013, pp. 1716-1725.

33. Yu, W., Hodges, D. H., Volovoi, V., and Cesnik, C. E. S. "On Timoshenko-like modeling of initially curved and twisted composite beams," International Journal of Solids and Structures Vol. 39, No. 19, 2002, pp. 5101-5121.

34. Smith, E. C., and Chopra, I. "Aeroelastic Response, Loads, and Stability of a Composite Rotor in Forward Flight," AIAA Journal Vol. 31, No. 7, 1993, pp. 1265-1273. 
35. De Rosa, M. A., and Franciosi, C. "Exact and approximate dynamic analysis of circular arches using DQM," International Journal of Solids and Structures Vol. 37, No. 8, 2000, pp. 1103-1117.

36. Leissa, A. W. "On a curve veering aberration," Zeitschrift für angewandte Mathematik und Physik ZAMP Vol. 25, No. 1, 1974, pp. 99-111. 